\title{
Transition from ferromagnet to cluster-glass in
}

\author{
$\mathrm{La}_{1-\mathrm{x}} \mathrm{Tb}_{\mathrm{x}} \mathrm{Mn}_{1 / 2} \mathrm{Sc}_{1 / 2} \mathrm{O}_{3}$.
}

J. Blasco, ${ }^{1}{ }^{*}$ V. Cuartero, ${ }^{1}$ J. García ${ }^{1}$ and J. A. Rodríguez-Velamazán. ${ }^{1,2}$

${ }^{1}$ Instituto de Ciencia de Materiales de Aragón and Departamento de Física de la Materia Condensada, CSIC-Universidad de Zaragoza, c/ Pedro Cerbuna 12, 50009 Zaragoza, Spain.

${ }^{2}$ Institut Laue Langevin, Grenoble Cédex 38042, France.

\begin{abstract}
.
We report the structural and magnetic properties of the $\mathrm{La}_{1-\mathrm{x}} \mathrm{Tb}_{\mathrm{x}} \mathrm{Mn}_{1 / 2} \mathrm{Sc}_{1 / 2} \mathrm{O}_{3}$ series. $\mathrm{LaMn}_{1 / 2} \mathrm{Sc}_{1 / 2} \mathrm{O}_{3}$ shows a long range ferromagnetic ordering in agreement with a fully polarized Mn-sublattice. The substitution of La with Tb produces structural changes which affect the magnetic properties. This substitution leads to a contraction in the unit cell volume that mainly reduces the $\mathrm{M}-\mathrm{O}-\mathrm{M}$ bond angle $(\mathrm{M}=\mathrm{Mn}, \mathrm{Sc})$. The bending of this angle decreases the $\mathrm{Mn}-\mathrm{O}-\mathrm{Mn}$ superexchange interaction and it enhances the competition between nearestneighbours and next-nearest-neighbours interactions. Accordingly, the magnetic ground state changes from ferromagnetic to a glassy magnetic state. Large thermal irreversibility between zero-field cooled and field cooled conditions is observed for all samples. The study of the dynamic magnetic properties has been performed using the frequency dependent real part of ac magnetic susceptibility. The use of both Vogel-Fulcher law and conventional critical slowing down law yields similar good accuracy in the fits. The relaxation times obtained from both laws concurs with the existence of a cluster glass for $\mathrm{x} \geq 0.5$ samples.
\end{abstract}

Keywords: manganite, random magnet, multiferroic, chemical pressure, spin glass.

PACS: 75.50.Lk, 61.05.cp, 75.47.Lx, 61.05.cj, 61.05.fg, 75.50.Dd

\section{Corresponding author:}

Javier Blasco

Instituto de Ciencia de Materiales de Aragón \& Dep. Física de la Materia Condensada

CSIC \& Universidad de Zaragoza

C/ Pedro Cerbuna 12

50009 ZARAGOZA (Spain)

Phone: +34-976-762419

Fax: +34-976-761229

email: jbc@unizar.es 


\section{Introduction.}

The study of $\mathrm{RMnO}_{3}(\mathrm{R}=$ rare earth $)$ and its derivatives has revealed intriguing properties and fascinating materials including giant magnetoresistance and multiferroic compounds [1-3]. This is the result of the interplay among charge, orbital, spin and lattice degrees of freedom [4]. $\mathrm{Mn}^{3+}$ in $\mathrm{RMnO}_{3}$ has unpaired electrons in $e_{g}$ states becoming a strongly Jahn-Teller (JT) active cation. These compounds adopt the orthorhombic structure of a $\mathrm{GdFeO}_{3}$-type perovskite with Pbnm space group. The distorted environment around the $\mathrm{Mn}^{3+}$ is revealed by the presence of two types of bonds in the $x y$-plane. Two long Mn-O bonds of $\sim 2.15 \AA$ and two short ones of $\sim 1.92 \AA$ [5]. In this plane, each -Mn-O-Mn-O-Mn- line has an ordered sequence of -long-shortlong- bonds which could favour a long-range $e_{g}$ orbital order [6]. This ordering is useful to explain the sign of the magnetic exchange interactions in $\mathrm{LaMnO}_{3}$. According to the Goodenough-Kanamori rules [7], the abovementioned sequence of bonds favours a ferromagnetic (FM) ground state in the $x y$-plane while the interaction between consecutive planes is antiferromagnetic (AF). This yields the A-type AF structure of $\mathrm{LaMnO}_{3}$ [8].

The replacement of $\mathrm{La}^{3+}$ by heavier and smaller $\mathrm{R}^{3+}$, the so-called 'chemical pressure', leads to a decrease of the unit cell volume and the increase of strain in the crystal. The strain is relaxed by an enhancement of the cooperative rotation of the $\mathrm{MnO}_{6}$ octahedra which produces an increase of the Mn-O-Mn bond angle bending. The decrease of this bond angle also affects the magnetic ground state of $\mathrm{RMnO}_{3}$ compounds and $\mathrm{TbMnO}_{3}$ exhibits a sinusoidal order of the $\mathrm{Mn}^{3+}$ magnetic moments aligned along the b-axis $[9,10]$ while $\mathrm{HoMnO}_{3}$ adopts the E-type $\mathrm{AF}$ structure [11]. These changes have been explained by the interplay of competitive superexchange magnetic interactions between nearest-neighbours and next-nearest-neighbours [12].

Another interesting feature is the appearing of spontaneous magnetization in $\mathrm{LaMnO}_{3}$ by replacing $\mathrm{Mn}$ with a non-magnetic ion such as $\mathrm{Ga}^{3+}$ or $\mathrm{Sc}^{3+}[13,14]$. Two models have been reported to account for this property. The spin flipping of $\mathrm{Mn} \mathrm{e}_{\mathrm{g}}$-orbital in $\mathrm{Mn}$ atoms surrounded by $\mathrm{Ga}$ atoms [15] and the FM vibronic superexchange interaction coming from disordered and fluctuating Mn atoms with a JT distortion [16]. The main difference between both models concerns to the dimension of the FM interaction. In the flipping model, the replacement with a non-magnetic ion induces a strong FM interaction along the $z$-direction while in the vibronic model, this interaction is isotropic. In both models, the existence of distorted (dynamic or static) $\mathrm{JT} \mathrm{Mn}^{3+}$ cations is assumed but x-ray spectroscopy revealed the existence of regular $\mathrm{MnO}_{6}$ octahedra in $\mathrm{FM} \mathrm{LaMn}{ }_{1-\mathrm{x}} \mathrm{Ga}_{\mathrm{x}} \mathrm{O}_{3}(\mathrm{x}>0.5)$ compounds suggesting a more complex scenario [17]. This type of substitution has been scarcely studied in other R. In the case of $\mathrm{R}=\mathrm{Tb}$, the parent compound is a multiferroic system induced by the noncommensurate magnetic structure of $\mathrm{Mn}^{3+}$ moments [3,18]. The substitution of $\mathrm{Mn}$ with $\mathrm{Ga}$ in this compound is very detrimental for the developing of electrical ordering and it weakens the AF ordering of $\mathrm{Mn}$ atoms leading to a spin-glass-like phase [19]. There was no possible the preparation of $\mathrm{TbMn}_{1 / 2} \mathrm{Ga}_{1 / 2} \mathrm{O}_{3}$ due to the presence of a competitive garnet phase [19]. This problem does not exist when the $\mathrm{Mn}$ is substituted with $\mathrm{Sc}$ as the perovskite phase is stable in the whole $\mathrm{TbMn}_{1-\mathrm{x}} \mathrm{Sc}_{\mathrm{x}} \mathrm{O}_{3}$ series [20]. 
In this paper, we examine the effects of the $\mathrm{R}$ size ('chemical pressure') in the correlations between structural and magnetic properties of $\mathrm{RMn}_{1 / 2} \mathrm{Sc}_{1 / 2} \mathrm{O}_{3}$ samples. With this aim, we have prepared the full $\mathrm{La}_{1-\mathrm{x}} \mathrm{Tb}_{\mathrm{x}} \mathrm{Mn}_{1 / 2} \mathrm{Sc}_{1 / 2} \mathrm{O}_{3}$ series and a systematic study of the crystal structure and the magnetic phases is reported.

\section{Experimental results.}

$\mathrm{La}_{1-\mathrm{x}} \mathrm{Tb}_{\mathrm{x}} \mathrm{Mn}_{1 / 2} \mathrm{Sc}_{1 / 2} \mathrm{O}_{3}(\mathrm{x}=0,0.2,0.4,0.5,0.6,0.8,1)$ samples were synthesized using ceramic procedures. Stoichiometric amounts of $\mathrm{La}_{2} \mathrm{O}_{3}, \mathrm{~Tb}_{4} \mathrm{O}_{7}, \mathrm{MnCO}_{3}$ and $\mathrm{Sc}_{2} \mathrm{O}_{3}$ were mixed, ground and heated at $1000^{\circ} \mathrm{C}$ in air for $16 \mathrm{~h}$. The powders were ground, pressed into pellets and heated at $1250^{\circ} \mathrm{C}$ in a current flow of Ar for $18 \mathrm{~h}$. Finally, the pellets were reground, repressed and sintered at $1400^{\circ} \mathrm{C}$ in the same atmosphere of Ar for $36 \mathrm{~h}$. The samples were characterized by $\mathrm{X}$-ray powder diffraction (XRD) measurements showing the diffraction peaks typical of a $\mathrm{GdFeO}_{3}$-like structure. No impurities were observed in the patterns.

Step scans were collected between $15^{\circ}$ and $130^{\circ}$ in steps of $0.03^{\circ}$ at room temperature using a Rigaku D-Max system. The device was working at $40 \mathrm{kV}$ and $100 \mathrm{~mA}$ with a counting rate of 4 s. step $^{-1}$. A graphite monochromator was used to select $\mathrm{K}_{\alpha}$ radiation and the crystal structures were refined using the Fullprof program package.

Neutron powder diffraction experiments were performed using the D1B instrument at Institut Laue-Langevin, (Grenoble, France) working at $2.52 \AA$ wavelength. Graphite filters between the monochromator and the sample significantly reduce higher-order wavelength contamination. The samples $(\mathrm{x}=0,0.2,0.5$ and 1$)$ were contained in a cylindrical vanadium-can $(\varnothing=6 \mathrm{~mm})$ inside an Orange Cryostat (vanadium-tailed). Neutron thermodiffractograms between 2 and c.a. $120 \mathrm{~K}$, with heating rate of $0.5 \mathrm{~K} / \mathrm{min}$, were collected using a new detector with increased angular definition $\left(0.1^{\circ}\right)$ and angular coverage $\left(0^{\circ}<2\right.$ th $\left.<128^{\circ}\right)$. The LAMP software [21] was used for data reduction.

Magnetic properties were measured using a Superconducting Quantum Interference Device (SQUID) magnetometer from Quantum Design in temperature ranging from $5 \mathrm{~K}$ to $300 \mathrm{~K}$. Hysteresis loops were measured in the same instrument up to $5 \mathrm{~T}$ magnetic fields. Initial ac magnetic susceptibility was measured with a fixed alternating field of 4 Oe and a set of frequencies ranging between $2.7 \mathrm{~Hz}$ and $1 \mathrm{KHz}$.

\section{Results and discussion.}

\subsection{Diffraction measurements.}

All samples show x-ray patterns typical of an orthorhombic perovskite without secondary phases. They were refined in the Pbnm space group and the results are summarized in table 1 . The substitution of La with $\mathrm{Tb}$ affects significantly the lattice parameters as can be seen in the figure 1 . The length of both $a$ - and $c$-axes strongly decreases as the Tb content increases. However, the b-axis shows the opposite trend with a slight increase. Accordingly, the orthorhombic distortion in the $a b$-plane rises with diminishing the rare earth size. 
The unit cell volume shows a continuous decrease with increasing the $\mathrm{x}$-value along the whole $\mathrm{La}_{1-\mathrm{x}} \mathrm{Tb}_{\mathrm{x}} \mathrm{Mn}_{1 / 2} \mathrm{Sc}_{1 / 2} \mathrm{O}_{3}$ series. This must be ascribed to the smaller ionic radius [22] of $\mathrm{Tb}^{3+}$ cations with respect to $\mathrm{La}^{3+}$ (lanthanide contraction) and indicates an effective 'chemical pressure'. Regarding the atomic coordinates, the replacement of Tb by La moves the atomic positions of $\mathrm{R}(\mathrm{R}=\mathrm{La}$ or $\mathrm{Tb})$ and $\mathrm{O}$ away from the ideal values of a cubic perovskite. For instance, the ideal cubic position for $\mathrm{R}$ atoms would be $\left(\begin{array}{lll}0 & 0 & 1 / 4\end{array}\right)$ in table 1 . These shifts have different consequences in the interatomic distances as can be seen in the figure 2 . Individual $\mathrm{R}$ $\mathrm{O}$ distances monotonically decrease with increasing the $\mathrm{Tb}$ content (see Fig. $2 \mathrm{~b}$ ) in agreement with the abovementioned smaller ionic radius. This effect leads to an overall contraction of the $\mathrm{RO}_{9}$ polyhedron. However, the individual $\mathrm{M}-\mathrm{O}$ bond lengths $(\mathrm{M}=\mathrm{Mn}$ or $\mathrm{Sc}$ ) show small changes after the substitution of $\mathrm{La}$ with $\mathrm{Tb}$. As the $\mathrm{Tb}$ content increases, the M-O2 distance slightly increases while the M-O1 decreases. Both changes seem to be coupled and the average $\mathrm{M}-\mathrm{O}$ bond length remains almost unchanged. Moreover, $\mathrm{MO}_{6}$ tends towards a typical JahnTeller distortion of an octahedral environment (composed by 4 short and 2 long M-O bond lengths) as the average R-size diminishes.

In accordance to the previous changes, another structural effect of the R-size diminution is the increase of the $\mathrm{MO}_{6}$ octahedra tilting. Such a tilting is characteristic of this type of orthorhombic perovskites and it occurs when the $\mathrm{R}^{3+}$ cation is too small for its 12 coordinate cavity in the cubic perovskite structure. Figure 3 shows how the M-O-M bond angle shrinks by $\sim 9^{\circ}$ when La is completely substituted with $\mathrm{Tb}$. The decrease seems to be almost linear for both apical (M-O1-M) and basal (M-O2-M) bond angles along the whole series.

Neutron diffraction patterns were measured to test the existence of long range magnetic ordering in these samples. The temperature dependence of these patterns for $\mathrm{La}_{1}$ ${ }_{x} \mathrm{~Tb}_{\mathrm{x}} \mathrm{Mn}_{1 / 2} \mathrm{Sc}_{1 / 2} \mathrm{O}_{3}(\mathrm{x}=0,0.2$ and 0.5$)$ samples is shown in the figure 4. There are no noticeable changes in the neutron patterns of $\mathrm{La}_{1 / 2} \mathrm{~Tb}_{1 / 2} \mathrm{Mn}_{1 / 2} \mathrm{Sc}_{1 / 2} \mathrm{O}_{3}$ (Fig. 4a) indicating the lack of magnetic ordering for this sample in agreement with the results reported for $\mathrm{TbMn}_{1 / 2} \mathrm{Sc}_{1 / 2} \mathrm{O}_{3}$ [20]. However, the patterns of $\mathrm{LaMn}_{1 / 2} \mathrm{Sc}_{1 / 2} \mathrm{O}_{3}$ and $\mathrm{La}_{0.8} \mathrm{~Tb}_{0.2} \mathrm{Mn}_{1 / 2} \mathrm{Sc}_{1 / 2} \mathrm{O}_{3}$ show a sudden increase in the intensity of the first FM peak which corresponds to the $(110)+(002)$ nuclear reflections and suggests the existence of a FM ground state for both samples. The orthorhombic distortion did not allow determining the spin orientation from only neutron powder diffraction so the patterns were refined with the spins located in the body diagonal. In these conditions, the refined magnetic moments at $2.5 \mathrm{~K}$ were 3.6(1) and 2.5(1) $\mu_{\mathrm{B}}$ per $\mathrm{Mn}$ atom for $\mathrm{LaMn}_{1 / 2} \mathrm{Sc}_{1 / 2} \mathrm{O}_{3}$ and $\mathrm{La}_{0.8} \mathrm{~Tb}_{0.2} \mathrm{Mn}_{1 / 2} \mathrm{Sc}_{1 / 2} \mathrm{O}_{3}$, respectively. The former value is close to the theoretical spin-only contribution from $\mathrm{Mn}^{3+}$ cation $\left(4 \mu_{\mathrm{B}}\right)$ and nicely agrees with the experimental value observed in $\mathrm{LaMn}_{1 / 2} \mathrm{Ga}_{1 / 2} \mathrm{O}_{3}$ [13]. The later value confirms a FM ordering for a significant part of the $\mathrm{Mn}^{3+}$ cations in the $\mathrm{La}_{0.8} \mathrm{~Tb}_{0.2} \mathrm{Mn}_{1 / 2} \mathrm{Sc}_{1 / 2} \mathrm{O}_{3}$ sample.

Figure 4(d) compares the temperature dependence of the intensity for the first FM peak for the three samples. No anomaly is observed for $\mathrm{La}_{1 / 2} \mathrm{~Tb}_{1 / 2} \mathrm{Mn}_{1 / 2} \mathrm{Sc}_{1 / 2} \mathrm{O}_{3}$ on cooling while the intensity of this peak starts to grow at $50 \mathrm{~K}$ for $\mathrm{LaMn}_{1 / 2} \mathrm{Sc}_{1 / 2} \mathrm{O}_{3}$ achieving saturation at around $10 \mathrm{~K}$. In the case of $\mathrm{La}_{0.8} \mathrm{~Tb}_{0.2} \mathrm{Mn}_{1 / 2} \mathrm{Sc}_{1 / 2} \mathrm{O}_{3}$, the peak begins to grow at $\sim 35 \mathrm{~K}$ reaching a maximum value at $\sim 6 \mathrm{~K}$ with a small drop at lower temperatures. 


\subsection{Magnetic measurements.}

Magnetization measurements were also conducted on these compounds. At high temperature, all samples behave as conventional paramagnets. These data are displayed as the inverse of molar susceptibility measured at $100 \mathrm{Oe}\left(\chi_{\mathrm{M}}=\mathrm{M} / \mathrm{H}\right)$ versus temperature (Figure 5). The straight lines observed at high temperature indicate that the Curie-Weiss law $-\chi_{M}=\mathrm{C} /(\mathrm{T}-\theta)-$ is obeyed in a wide temperature range. The data were fitted to the Curie-Weiss law in the temperature range $90 \mathrm{~K} \leq \mathrm{T} \leq 300 \mathrm{~K}$ for all samples with the only exception of $\mathrm{LaMn}_{1 / 2} \mathrm{Sc}_{1 / 2} \mathrm{O}_{3}$ with a shorter linear region. In this case, the fit was performed between 150 and $300 \mathrm{~K}$ (see Fig. 5). The fits lead to the values summarized in table 2. The Curie Constant (C) increases as the $\mathrm{Tb}$ content does. Accordingly, the effective paramagnetic moments ( $\left.\rho_{\text {eff }}\right)$ follow the same trend. $\rho_{\text {eff }}$ can be accounted for by the contribution of both paramagnetic cations, $\mathrm{Mn}^{3+}$ and $\mathrm{Tb}^{3+}$ $\rho_{\text {theo }}{ }^{2}=1 / 2 \rho_{\mathrm{Mn}}{ }^{2}+\mathrm{x} \rho_{\mathrm{Tb}}{ }^{2}$ - We have taken the experimental values of 4.9 and 9.5 as $\rho_{\mathrm{Mn}}\left(\mathrm{Mn}^{3+}\right)$ and $\rho_{\mathrm{Tb}}\left(\mathrm{Tb}^{3+}\right)$, respectively [23]. Overall, the agreement between experimental and theoretical moments is good and the highest difference is observed for $\operatorname{TbMn}_{1 / 2} \mathrm{Sc}_{1 / 2} \mathrm{O}_{3}$. The positive value of the Weiss parameter $(\theta)$ for $\mathrm{LaMn}_{1 / 2} \mathrm{Sc}_{1 / 2} \mathrm{O}_{3}$ reveals that $\mathrm{FM}$ interactions are predominant in this compound. As $\mathrm{La}$ is replaced by $\mathrm{Tb}$, the value of $\theta$ diminishes and changes sign for $\mathrm{x} \geq 0.6$ indicating a prevalence of antiferromagnetic interactions for the Tb-rich samples.

At low temperatures, anomalies are observed in the magnetization curves for all samples. Figure 6 shows the molar susceptibility under zero-field- and field-cooled (ZFC and FC) conditions of $\mathrm{La}_{1-\mathrm{x}} \mathrm{Tb}_{\mathrm{x}} \mathrm{Mn}_{1 / 2} \mathrm{Sc}_{1 / 2} \mathrm{O}_{3}$ samples under an applied field of 100 Oe. The two curves diverge at a characteristic temperature ( $\mathrm{T}_{\text {irr }}$ ) giving rise to two branches for all samples but differences are found depending on the $\mathrm{La} / \mathrm{Tb}$ ratio. In the La-parent compound, the $\mathrm{ZFC}$ branch has a strong peak at $\mathrm{T}_{\text {peak }} \sim 28 \mathrm{~K}$. Below this temperature, the magnetization of the sample continuously decreases with decreasing temperature. The FC curve instead, shows a continuous increase with decreasing temperature with a maximum slope at $T_{C}=50 \mathrm{~K}$ which agrees with $T_{\text {irr. }}$. The shape of the FC curve for this sample resembles a FM transition. The Tb substitution for La leads to a decrease of both $\mathrm{T}_{\text {peak }}$ and $\mathrm{T}_{\text {irr }}$ together with a shrinkage of the magnetization at low temperature. In the case of $\mathrm{La}_{0.8} \mathrm{~Tb}_{0.2} \mathrm{Mn}_{1 / 2} \mathrm{Sc}_{1 / 2} \mathrm{O}_{3}$ sample, the ZFC curve is similar to the parent compound with the aforementioned decrease in magnitude. However, the $\mathrm{FC}$ branch also undergoes a maximum at $14.5 \mathrm{~K}$ and then it shows a small drop on cooling. Such behaviour is not expected either for a conventional FM transition or for a system of noninteracting superparamagnetic clusters where FC magnetization increases monotonically with decreasing temperature [24]. The peak in the FC curves is observed up to $\mathrm{x}=0.5$ compositions. For $\mathrm{x} \geq 0.6, \mathrm{FC}$ curves again show a steady increase with decreasing temperature. In this composition range, the maximum in the $\mathrm{ZFC}$ branch is more flattened and there is not a strong decay below $T_{\text {peak. }}$ This effect might be ascribed to the paramagnetism of $\mathrm{Tb}^{3+}$ cations whose contribution rises as $\mathrm{X}$-value does. $\mathrm{T}_{\text {peak }}$ continuously decreases with increasing the $\mathrm{Tb}$ content suggesting a weakness of the FM interactions with increasing the 'chemical pressure' in the unit cell. The origin of thermal irreversibility seems to be common for all samples although the neutron diffraction patterns revealed the presence of long range FM ordering in $x=0$ and $x=0.2$ 
samples. It might be ascribed to the presence of different competing magnetic interactions dominating differently thermal cycling but domain walls can also play a role in FM samples.

The peak in the ZFC branch becomes more rounded and flattened shifting towards lower temperature with increasing the applied field. For instance, Figure 7 compares FC and ZFC curves of two selected samples under 100 and 2500 Oe. The increase of the field also decreases $\mathrm{T}_{\text {irr }}$ which appears below the peak at fields of 2500 Oe. In Tb-rich compounds, the peak becomes a shoulder as can be seen for $\mathrm{x}=0.6$ in Fig. 7. Similar features are reported for both spin and cluster glass systems and stronger magnetic fields usually vanish the magnetic irreversibility $[25,26]$.

Isothermal magnetic measurements were collected at $5 \mathrm{~K}$. The results are shown in the Figure 8. $\mathrm{LaMn}_{1 / 2} \mathrm{Sc}_{1 / 2} \mathrm{O}_{3}$ shows a hysteresis loop typical of a quite hard FM material with a coercive field of $\sim 600$ Oe and a remanence of $0.53 \mu_{\mathrm{B}} / f$.u. Magnetic saturation is almost reached at 50 KOe with a value of $3.8 \mu_{\mathrm{B}} / \mathrm{Mn}$, very close to the expected value of $4 \mu_{\mathrm{B}} / \mathrm{Mn}$ for the $\mathrm{Mn}$ sublattice fully polarized. This value agrees with the magnetic moment obtained from the neutron diffraction pattern. A hardening of the FM contribution together with an increase in the paramagnetic signal at high fields is observed in $\mathrm{La}_{0.8} \mathrm{~Tb}_{0.2} \mathrm{Mn}_{1 / 2} \mathrm{Sc}_{1 / 2} \mathrm{O}_{3}$. The coercive field for this sample reaches a value of $\sim 1500$ Oe. Further substitution of La with $\mathrm{Tb}(\mathrm{x} \geq 0.4)$ changes significantly the magnetic loop with a noticeable diminution of the initial magnetization. This change agrees with variation of the magnetic ground state in the series described below. Regarding the high field contribution, a rise in the paramagnetic signal with increasing $\mathrm{x}$ is expected (increase of $\mathrm{Tb}$ content) but this trend is not linear with the composition. Samples with $0.4 \leq \mathrm{x} \leq 0.6$ show almost identical hysteresis loop characterized by a strong inclination with values of coercivity similar to $\mathrm{LaMn}_{1 / 2} \mathrm{Sc}_{1 / 2} \mathrm{O}_{3}$ but with a very low remanence $\left(0.06 \mu_{\mathrm{B}} /\right.$ f.u. $)$. Further increase in the $\mathrm{Tb}$ content $(\mathrm{x}=0.8$ and $\mathrm{x}=1)$ increases the magnetization at high fields but the loop shape is similar. Only the $\mathrm{TbMn}_{1 / 2} \mathrm{Sc}_{1 / 2} \mathrm{O}_{3}$ sample shows a curvature in the magnetization at high fields that resembles an incipient magnetic saturation.

In order to characterize the presence of dynamic processes in the magnetic anomalies, ac magnetic susceptibility was measured in representative $\mathrm{La}_{1-\mathrm{x}} \mathrm{Tb}_{\mathrm{x}} \mathrm{Mn}_{1 / 2} \mathrm{Sc}_{1 / 2} \mathrm{O}_{3}$ samples $(\mathrm{x}=0$, $0.2,0.5$ and 1). Figure 9 shows the temperature dependence of initial ac magnetic susceptibility at different frequencies $(f=\omega / 2 \pi)$ of the alternating field. The real part $\left(\chi^{\prime}\right)$ shows a peak whose intensity decreases with increasing $f$. The characteristic temperature of the maximum $\left(T_{p}\right)$ appears at a bit higher temperature than the corresponding dc measurement (compare Fig. 7 and 9 ). Figure 9 also shows the imaginary part ( $\chi$ ") which also shows a peak at lower temperatures than $\chi$ '. In fact, the peak in $\chi^{\prime}$-curves is close to the inflection point in the $\chi$ "-curves. These peaks are usually reported in spin glasses, cluster glasses and superparamagnetic nanoparticles [27-29] and they are ascribed to freezing (or blocking) processes of spins (or nanoparticles). In such systems, both peaks are shifted towards higher temperatures as the frequency is increased. In the present system, significant differences can be noticed depending on the $\mathrm{La} / \mathrm{Tb}$ ratio. In the case of $\mathrm{LaMn}_{1 / 2} \mathrm{Sc}_{1 / 2} \mathrm{O}_{3}$ (Fig. 9a), the value of $\mathrm{T}_{\mathrm{p}}$ does not change monotonically with $f$ and the maximum frequency shift, defined as $\left.p=\Delta T_{p} /\left[T_{p} \Delta \log f\right)\right]$, is less than 0.002 , a variation within the limit errors and quite smaller than a conventional spin-glass [29]. Moreover, the 
magnitude of both $\chi$ ' and $\chi$ " at $\mathrm{T}_{\mathrm{p}}$ decrease with increasing $f$, an unusual feature in spin-glass where the diminution of $\chi^{\prime}(f)$ is correlated with an increase in the $\chi^{\prime \prime}(f)$ magnitude because of the phase lag of the ac driving field [29]. Bearing in mind the presence of long range FM ordering, the dynamic behavior in this sample might be ascribed to dynamic processes of domain walls. In this way, strong frequency dependence was found in some magnetic alloys [30] that were explained as a consequence of magnetic disaccomodation phenomena coming from the motion of domain walls coupled to intrinsic defects acting as pining forces [31]. This type of phenomena is thought to be present in related Mn-based perovskites [32,33]. In the present system, the significant concentration of non-magnetic cations in the M-sublattice and its random distribution may act as pinning centers coupled to the domain walls [31].

$\mathrm{La}_{0.8} \mathrm{~Tb}_{0.2} \mathrm{Mn}_{1 / 2} \mathrm{Sc}_{1 / 2} \mathrm{O}_{3}$ shows similar changes in the magnitude of $\chi^{\prime}$ and $\chi$ ' at $\mathrm{T}_{\mathrm{p}}$ but in this case, a noticeable shift towards higher temperatures with increasing $f$ is also observed with $\mathrm{p}=0.008$ for the peak in $\chi^{\prime}$-curve. This value is small but comparable to the one observed in some metallic spin-glasses [29]. Remembering that neutron diffraction revealed the existence of FM ordering in this sample without reaching the theoretical full magnetization, a possible explanation is the coexistence of FM and glassy phases in this sample as reported in related perovskites [34]. Moreover, there is a crossover in the magnitude of $\chi$ " below $19 \mathrm{~K}$ and it follows the usual behaviour of a spin-glass. This effect might be related to an incipient reentrant behaviour that was previously intuited in the temperature dependence of the FM peak (see Fig. 4d).

The magnitudes and of $\chi$ ' and $\chi$ " for $\mathrm{La}_{0.5} \mathrm{~Tb}_{0.5} \mathrm{Mn}_{1 / 2} \mathrm{Sc}_{1 / 2} \mathrm{O}_{3}$ and $\mathrm{TbMn}_{1 / 2} \mathrm{Sc}_{1 / 2} \mathrm{O}_{3}$ follow the usual behaviour of a spin-glass (Fig. 9c and 9d) with opposite trends as frequency increases $[29,35$. The peak shift of the real component achieves values of $p \sim 0.05$ for both compounds, typical of insulating spin-glasses [29]. In order to characterize the nature of the freezing process, the frequency dependence of $T_{p}$ in Fig. 9b-9d was analysed. First of all, the Arrhenius law was tested. This law is obeyed by non-interacting superparamagnetic clusters and in our case it is written as: $\tau=\tau_{0} \exp \left(\mathrm{E}_{\mathrm{A}} / \mathrm{k}_{\mathrm{B}} \mathrm{T}_{\mathrm{p}}\right)$; where $\mathrm{E}_{\mathrm{A}}$ is the anisotropy energy barrier and $\tau$ is a characteristic time describing the dynamical fluctuation time scale $(\tau=2 \pi / \omega)$ [29]. The best fits (not shown) yields in these samples unphysical values with $\mathrm{E}_{\mathrm{A}} / \mathrm{k}_{\mathrm{B}}>1000 \mathrm{~K}$ and $\tau_{0} \sim 10^{-30} \mathrm{~s}$.

There are two approximations to account for interacting magnetic entities, the phenomenological Vogel-Fulcher law and a power law coming from a dynamical scaling near a transition at $T^{*}$. In the first case, the expression is: $\tau=\tau_{0} \exp \left[\mathrm{E}_{\mathrm{A}} / \mathrm{k}_{\mathrm{B}}\left(\mathrm{T}_{\mathrm{p}}-\mathrm{T}_{0}\right)\right]$; and the term $\mathrm{T}_{0}$, sometimes named as the Vogel-Fulcher temperature, accounts for the interaction among spins or magnetic clusters. In the second case, it is assumed a true phase transition with a critical temperature $T^{*}$. The relationship between $\tau$ and the correlation length $\xi$ is $\tau \sim \xi^{z}$ and since $\xi$ diverges when $\mathrm{T}_{\mathrm{p}}(f)$ approaches $\mathrm{T}^{*}$ as $\xi \sim\left[\mathrm{T}_{\mathrm{p}} /\left(\mathrm{T}_{\mathrm{p}}-\mathrm{T}^{*}\right)\right]^{\cup}[29]$, the power law takes the form of $\tau=\tau^{*}\left[T_{p} /\left(T_{p}-T^{*}\right)\right]^{z v}$ where the product $\mathrm{zu}$ is the dynamical exponent.

We have proceeded as indicated in ref. 36 to obtain the values of $\mathrm{T}_{0}$ and $\mathrm{T}^{*}$. The linear relationships of $[\Delta \operatorname{Tp}(f) / \Delta \operatorname{Ln} f]^{1 / 2}$ vs $\operatorname{Ln} f$ yields $T_{0}$ while the plot of $\operatorname{Ln} \Delta \operatorname{Tp}(f) / \Delta \operatorname{Ln} f v s \operatorname{Ln} f$ gives $\mathrm{T}^{*}$. The results are collected in the table 3. Then, the Vogel-Fulcher law has been probed 
by plotting $1 /\left(\mathrm{T}_{\mathrm{p}}-\mathrm{T}_{0}\right)$ vs $\operatorname{Ln} \tau$ as can be seen in the figure $10 \mathrm{a}$. The linear dependence is clear and the best values of the fits are included in the table 3 . The three samples show reasonable $E_{A} / k_{B}$ and $\tau_{0}$ parameters [36]. $\mathrm{La}_{0.8} \mathrm{~Tb}_{0.2} \mathrm{Mn}_{1 / 2} \mathrm{Sc}_{1 / 2} \mathrm{O}_{3}$ with a FM phase shows the smallest activation energy and the longer relaxation time. For the three samples, $\tau_{0}$ is longer than the values expected for conventional spin glasses $\left(10^{-13} \mathrm{~s}\right)$. However, $\tau_{0}$ is determined by the spin flip of the atomic moment in spin glasses and large $\tau_{0}$ values could be ascribed to nanosized spin clusters instead of atomic spins [37]. In order to test if the dynamics of these samples can be accounted for by a critical slowing down law, we have plotted $\operatorname{Ln}\left[\mathrm{T}_{\mathrm{p}} /\left(\mathrm{T}_{\mathrm{p}}-\mathrm{T}^{*}\right)\right]$ vs $\operatorname{Ln} \tau$ in the Fig. 10b. Similar linear relationships are observed for the three samples with similar accuracy of the linear fits. The best fit values are also summarized in the table 3 . The value of zo holds good in the range between 4.2 and 10.2 found in glassy compounds [36] while $\tau^{*}$ shows higher values than conventional spin glasses but in agreement with cluster glasses [34,37].

\section{Conclusions.}

This study has clarified the role of the chemical pressure on $\mathrm{RMn}_{1 / 2} \mathrm{Sc}_{1 / 2} \mathrm{O}_{3}$ perovskites. Neutron diffraction reveals that $\mathrm{LaMn}_{1 / 2} \mathrm{Sc}_{1 / 2} \mathrm{O}_{3}$ develops a true long range FM ordering instead of undergoing a spin glass to FM transition in the presence of an external magnetic field as was thought in previous studies [14]. The substitution of La with Tb causes a decrease in the unit cell volume that affects differently to the two metal transition sublattices. While the R-O bond length decreases monotonically with increasing the $\mathrm{Tb}$ content, the $\mathrm{M}-\mathrm{O}$ distance remains unchanged due to the absence of changes in the valence of $\mathrm{Mn}^{3+}\left(\mathrm{and}_{\mathrm{Sc}^{3+}}\right.$ ). This produces a strain in the cell which is relieved by bending the M-O-M bond angle. The average M-O-M bond angle goes from a value of $\sim 152^{\circ}$ for $\mathrm{R}=\mathrm{La}$ to a value of $\sim 143.5^{\circ}$ for $\mathrm{R}=\mathrm{Tb}$. These samples exhibit a magnetic anomaly at a typical temperature whose magnitude decreases as the $\mathrm{M}-\mathrm{O}-\mathrm{M}$ bond angle does. This result suggests that the M-O-M bending weakens the superexchange FM interactions between nearest-neighbours and strengthens the antiferromagnetic interactions between next-nearest-neighbours as occurs in the $\mathrm{RMnO}_{3}$ system [12].

The competition between FM and AFM interactions together with the random distribution of magnetic $\mathrm{Mn}^{3+}$ cations favours magnetic disorder. The FM ordering is no longer fully achieved in the $\mathrm{La}_{0.8} \mathrm{~Tb}_{0.2} \mathrm{Mn}_{1 / 2} \mathrm{Sc}_{1 / 2} \mathrm{O}_{3}$ sample where there is a coexistence of FM and glassy magnetic states as observed in Fe-doped manganites [34]. The further increase of Tb substitution leads to nanosized magnetic clusters whose magnetic properties behave as spin glasses. All samples show magnetic irreversibility (ZFC-FC) in the temperature dependence of the magnetization and dynamic behaviour in the ac susceptibility. In $\mathrm{LaMn}_{1 / 2} \mathrm{Sc}_{1 / 2} \mathrm{O}_{3}$, the magnitude of $\chi$ ' and $\chi$ " peaks diminishes as frequency increases but there is no significant shift in the temperature peak. It could be ascribed to domain wall movements within a pinning potential well induced by the presence of a high amount of non-magnetic atoms in the Mn-sublattice. Both FZ-ZFC irreversibility and frequency dependence may arise from domain wall motions coupled to intrinsic defects as observe in alloys and related perovskites [30-33]. The frequency dependence increases as the size of the magnetic cluster diminishes and $\mathrm{La}_{1-\mathrm{x}} \mathrm{Tb}_{\mathrm{x}} \mathrm{Mn}_{1 / 2} \mathrm{Sc}_{1 / 2} \mathrm{O}_{3}$ samples with $\mathrm{x} \geq 0.5$ behave as conventional spin glasses. $T_{p}$ increases as frequency does and the 
magnitude of $\chi$ '- and $\chi$ "-peak follows opposite trends. The observed frequency dependence of the peak in $\chi^{\prime}$-curve can be analysed using both a Vogel-Fulcher law and a power law coming from the dynamic scale hypothesis. In both cases, the fits are equally good and the relaxation time constant $\tau_{0}$ (or $\tau^{*}$ ) shows larger values than the expected for conventional spin glasses suggesting the presence of magnetic clusters in these samples.

\section{Acknowledgements.}

The authors thank to the Servicio de difracción de rayos X from Zaragoza University for technical assistance and data acquisition. We also thank ILL and SPINS for neutron beam time allocation. Financial support from the Spanish MICINN (project FIS08-03951 and MAT200761621) and DGA (CAMRADS) is acknowledged. VC thanks their research grants from MICINN, respectively. 


\section{References.}

[1] Tokura Y 2000 Colossal Magnetoresistive oxides, Gordon\&Breach Science.

[2] Dagotto E, Hotta T and Moreo A 2001 Phys Rep. 344, 1.

[3] Kimura K, Goto T, Shintani H, Ishizka K, Arima T and Tokura Y 2003 Nature (London), 426, 55.

[4] Rao CNR and Raveau B 1998 Colossal Magnetoresistance, charge ordering and related properties of manganese oxides, World Scientific.

[5] Sánchez MC, Subías G, García J and Blasco J 2003 Phys. Rev. Lett. 90, 045503.

[6] Khomskii DI and Kugel KI 2003 Phys. Rev. B 67, 134401.

[7] Goodenough JB 1963 Magnetism and chemical bond, New York; Interscience.

[8] Wollan EO and Koehler WC 1955 Phys. Rev. 100, 545.

[9] Quezel S, Tcheou F, Rossatmignod J, Quezel G and Roudaut E 1977 Physica B 86-88, 916.

[10] Blasco J, Ritter C, García J, De Teresa JM, Pérez-Cacho J and Ibarra MR 2000 Phys. Rev. B 62, 5609.

[11] Muñoz A and Casáis MT, Alonso JA, Martínez-Lope MJ, and Martínez JL and Fernández-Díaz MT 2001 Inorg. Chem. 40, 1020.

[12] Kimura T, Ishihara S, Shintani H, Arima T, Takahashi KT, Ishizaka K and Tokura Y 2003 Phys. Rev. B 68, 060403(R).

[13] Blasco J, García J, Campo J and Sánchez MC 2002 Phys. Rev. B 66, 174431.

[14] Goodenough JB, Dass RI and Zhou J 2002 Sol. State Sci.4, 297.

[15] Farrell J and Gehring GA 2004 New J. Phys. 6, 168.

[16] Zhou J-S and Goodenough JB 2003 Phys. Rev B 68, 144406.

[17] Sánchez MC, Subías G, García J and Blasco J 2004 Phys. Rev. B 69, 184415.

[18] Kenzelmann M, Harris AB, Jonas S, Broholm C, Schefer J, Kim XB, Zhang CL, Cheong S-W, Vajk OP and Lynn JW 2005 Phys. Rev. Lett. 95, 087206.

[19] Cuartero V, Blasco J, García J, Subías G and Sánchez MC 2010 J. Phys.: Conf. Ser. 200, 012024.

[20] Cuartero V, Blasco J, García J, Subías G, Ritter C and Rodríguez-Velamazán JA 2010 Phys. Rev. B 81, 224117.

[21] Richard D, Ferrand M and Kearley GJ 1996 J. Neutron Res. 4, 33; LAMP, the Large Array Manipulation Program, available at http://www.ill.fr/data_treat/lamp/lamp.html.

[22] Shannon RD 1976 Acta Cryst. A32, 751.

[23] Jiles D 1998 Introduction to magnetism and magnetic materials, p. 243, London: Chapman\&Hall.

[24] Bitoh T, Ohba K, Takamatsu M, Shirane T and Chikazawa S 1995 J. Phys. Soc. Jpn. 64, 1035.

[25] Kenning GG, Chu D and Orbach R 1991 Phys. Rev. Lett. 66, 2923.

[26] Yusuf SM, Sahana M, Dörr K, Rö ler UK and Müller K-H 2002 Phys. Rev. B 66, 064414.

[27] De K, Patra M, Majumdar S and Giri S 2007 J. Phys.D: Appl. Phys. 40, 7614.

[28] Djurberg C, Svedlindh P, Norblad P, Hansen MF, Bodker F and Morup S 1997 Phys. Rev. Lett. 79, 5154.

[29] Mydosh JA 1993 Spin glasses: An experimental introduction, Taylor\&Francis.

[30] Chen DX, Skumryev V and Coey JMD 1996 Phys. Rev. B 53, 15014.

[31] García LM, Bartolomé J, Lázaro FJ, de Francisco C and Muñoz JM 1996 Phys. Rev. B 54, 15238.

[32] Blasco J, García J, Sánchez MC, Campo J, Subías G and Pérez-Cacho J 2002 Eur. Phys. J. B 30, 469.

[33] Muroi M, Street R, Cochrane JW and Russell GJ 2001 Phys. Rev. B 64, 024423.

[34] De K, Majumdar S and Giri S 2007 J. Phys.D: Appl. Phys. 40, 5810.

[35] Lakshami LS and Nigam AK 2011 J. Phys.: Cond. Matter. 23, 086006.

[36] Souletie J and Tholence JL 1985 Phys. Rev. B 32, 516.

[37] Mukadam MD, Yusuf SM, Sharma P, Kulshreshtha SK and Dey GK 2005 Phys. Rev. B 72, 174408. 
Table 1. Lattice parameters, fractional coordinates, temperature factors and reliability factors for $\mathrm{La}_{1}$ ${ }_{\mathrm{x}} \mathrm{Tb}_{\mathrm{x}} \mathrm{Mn}_{1 / 2} \mathrm{Sc}_{1 / 2} \mathrm{O}_{3}$ refined in the Pbnm space group, atoms are located as follow. $\mathrm{RE}(\mathrm{La} / \mathrm{Tb})$ and $\mathrm{O} 1$ at 4c: $\mathrm{x}, \mathrm{y}, 1 / 4 ; \mathrm{M}(\mathrm{Mn} / \mathrm{Sc})$ at $4 \mathrm{~b}: 1 / 2,0,0 ; \mathrm{O} 2$ at $8 \mathrm{~d}: \mathrm{x}, \mathrm{y}, \mathrm{z}$.

\begin{tabular}{r|c|c|c|c|c|c|c} 
& $\mathrm{x}=0$ & $\mathrm{x}=0.2$ & $\mathrm{x}=0.4$ & $\mathrm{x}=0.5$ & $\mathrm{x}=0.6$ & $\mathrm{x}=0.8$ & $\mathrm{x}=1$ \\
\hline $\mathrm{a}(\AA)$ & $5.59906(7)$ & $5.55229(6)$ & $5.51228(8)$ & $5.48231(7)$ & $5.46868(12)$ & $5.42676(9)$ & $5.39762(12)$ \\
$\mathrm{b}(\AA)$ & $5.71277(6)$ & $5.72091(6)$ & $5.73626(8)$ & $5.73437(7)$ & $5.75024(12)$ & $5.76296(10)$ & $5.72783(14)$ \\
$\mathrm{c}(\AA)$ & $7.95235(9)$ & $7.90574(9)$ & $7.86174(11)$ & $7.82560(10)$ & $7.80645(16)$ & $7.74782(13)$ & $7.76006(17)$ \\
$\mathrm{RE}: \mathrm{x}$ & $0.9913(1)$ & $0.9899(2)$ & $0.9886(2)$ & $0.9876(2)$ & $0.9868(2)$ & $0.9858(2)$ & $0.9847(2)$ \\
$\mathrm{y}$ & $0.0421(1)$ & $0.0477(1)$ & $0.0542(1$ & $0.0581(1)$ & $0.0611(1)$ & $0.0655(2)$ & $0.0657(1)$ \\
$\mathrm{z}$ & $1 / 4$ & $1 / 4$ & $1 / 4$ & $1 / 4$ & $1 / 4$ & $1 / 4$ & $1 / 4$ \\
$\mathrm{~B}(\AA)$ & $0.38(1)$ & $0.31(1)$ & $0.36(1)$ & $0.51(1)$ & $0.36(1)$ & $0.23(1)$ & $0.27(2)$ \\
$\mathrm{M}: \mathrm{B}(\AA)$ & $0.09(2)$ & $0.21(3)$ & $0.23(3)$ & $0.12(2)$ & $0.16(3)$ & $0.13(3)$ & $0.16(5)$ \\
$\mathrm{O} 1: \mathrm{x}$ & $0.0899(11)$ & $0.0926(12)$ & $0.0974(12)$ & $0.1027(12)$ & $0.1097(13)$ & $0.1109(14)$ & $0.1145(14)$ \\
$\mathrm{y}$ & $0.4793(9)$ & $0.4703(11)$ & $0.4646(11)$ & $0.4604(11)$ & $0.4678(12)$ & $0.4650(14)$ & $0.4606(14)$ \\
$\mathrm{z}$ & $1 / 4$ & $1 / 4$ & $1 / 4$ & $1 / 4$ & $1 / 4$ & $1 / 4$ & $1 / 4$ \\
$\mathrm{~B}(\AA)$ & $0.73(7)$ & $0.68(9)$ & $0.42(9)$ & $0.59(8)$ & $0.44(9)$ & $0.47(8)$ & $0.49(9)$ \\
$\mathrm{O} 2: \mathrm{x}$ & $0.7123(8)$ & $0.7088(9)$ & $0.7071(9)$ & $0.7007(8)$ & $0.7067(10)$ & $0.7010(10)$ & $0.6954(10)$ \\
$\mathrm{y}$ & $0.2951(7)$ & $0.2976(8)$ & $0.2999(9)$ & $0.3037(8)$ & $0.2995(9)$ & $0.3056(10)$ & $0.3117(11)$ \\
$\mathrm{z}$ & $0.0424(6)$ & $0.0494(6)$ & $0.0499(6)$ & $0.0529(5)$ & $0.0548(6)$ & $0.0568(7)$ & $0.0578(7)$ \\
$\mathrm{B}(\AA)$ & $0.73(7)$ & $0.68(9)$ & $0.42(9)$ & $0.59(8)$ & $0.44(9)$ & $0.47(8)$ & $0.49(9)$ \\
$\mathrm{R}_{\mathrm{p}} / \mathrm{R}_{\mathrm{wp}}(\%)$ & $6.5 / 7.9$ & $6.5 / 8.6$ & $6.1 / 8.2$ & $5.6 / 7.6$ & $6.0 / 8.1$ & $5.3 / 7.3$ & $5.3 / 6.7$ \\
$\mathrm{R}_{\text {Bragg }}(\%)$ & 3.5 & 3.9 & 4.2 & 4.7 & 3.7 & 4.3 & 3.8 \\
\hline
\end{tabular}

Table 2. Magnetic parameters - Curie constant, Weiss parameter, experimental and theoretical effective paramagnetic moments — obtained from the fits indicated in Fig.6.

\begin{tabular}{|c|c|c|c|c|}
\hline $\mathbf{x}$ & $\mathrm{C}\left(\mathrm{emu}^{-1} \mathrm{Kmol}^{-1}\right)$ & $\theta(\mathbf{K})$ & $\rho_{\text {eff }}\left(\mu_{B} f \cdot u^{-1}\right)$ & $\rho_{\text {theo }}\left(\mu_{\mathrm{B}} f . u_{.^{-1}}\right)$ \\
\hline 0 & 1.84 & 27.2 & 3.84 & 3.46 \\
\hline 0.2 & 3.647 & 3.5 & 5.40 & 5.48 \\
\hline 0.4 & 6.438 & 0.45 & 7.18 & 6.93 \\
\hline 0.5 & 7.523 & 0.14 & 7.76 & 7.56 \\
\hline 0.6 & 8.195 & -0.01 & 8.10 & 8.13 \\
\hline 0.8 & 10.030 & -0.11 & 8.96 & 9.17 \\
\hline 1 & 11.339 & -0.11 & 9.52 & 10.11 \\
\hline
\end{tabular}

Table 3. Best values for the parameters of the Vogel-Fulcher $\left(T_{0}, \tau_{0}\right.$ and $\left.E_{A} / K_{B}\right)$ and power laws $\left(T^{*}, \tau *\right.$ and $\left.z v\right)$ for from the fits of Fig. 10.

\begin{tabular}{c|ccc|ccc|c|} 
& \multicolumn{3}{|c|}{ Vogel-Fulcher } & \multicolumn{3}{c|}{ Power law } \\
\hline $\mathbf{X}$ & $\mathbf{T}_{\mathbf{0}} \mathbf{( K )}$ & $\tau_{\mathbf{0}}(\mathbf{s .})$ & $\mathbf{E}_{\mathbf{A}} / \mathbf{K}_{\mathbf{B}}(\mathbf{K})$ & $\mathbf{T}^{*}(\mathbf{K})$ & $\tau^{*}(\mathbf{s})$. & $\mathbf{z} \boldsymbol{)}$ \\
\hline 0.2 & 31.3 & $2.8 \cdot 10^{-6}$ & 9 & 31.8 & $4.3 \cdot 10^{-10}$ & 4.2 \\
0.5 & 14.6 & $3.0 \cdot 10^{-8}$ & 68 & 16.9 & $1.0 \cdot 10^{-9}$ & 8.7 \\
1 & 11.0 & $9.7 \cdot 10^{-9}$ & 45 & 12.5 & $1.4 \cdot 10^{-10}$ & 8.7 \\
\hline
\end{tabular}




\section{Figure captions.}

Figure 1. Evolution of the lattice parameters and unit cell volume along the $\mathrm{La}_{1-\mathrm{x}} \mathrm{Tb}_{\mathrm{x}} \mathrm{Mn}_{1 / 2} \mathrm{Sc}_{1 / 2} \mathrm{O}_{3}$ series.

Figure 2.- Interatomic distances between $\mathrm{M}(\mathrm{Mn} / \mathrm{Sc})$ and oxygen atoms (a) and between $\mathrm{R}(\mathrm{La} / \mathrm{Tb})$ and oxygens (b). $<\mathrm{M}-\mathrm{O}>$ and $<\mathrm{R}-\mathrm{O}>$ stands for average distances.

Figure 3. Evolution of the M-O-M bond angles for the $\mathrm{La}_{1-\mathrm{x}} \mathrm{Tb}_{\mathrm{x}} \mathrm{Mn}_{1 / 2} \mathrm{Sc}_{1 / 2} \mathrm{O}_{3}$ series.

Figure 4. Neutron thermodifractograms of (a) $\mathrm{TbMn}_{1 / 2} \mathrm{Sc}_{1 / 2} \mathrm{O}_{3}$ (b) $\mathrm{La}_{0.5} \mathrm{~Tb}_{0.5} \mathrm{Mn}_{1 / 2} \mathrm{Sc}_{1 / 2} \mathrm{O}_{3}$ and (c) $\mathrm{La}_{0.8} \mathrm{~Tb}_{0.2} \mathrm{Mn}_{1 / 2} \mathrm{Sc}_{1 / 2} \mathrm{O}_{3}$. (d) Temperature dependence of the first ferromagnetic peak for the three samples.

Figure 5. The inverse DC molar susceptibility of $\mathrm{La}_{1-\mathrm{x}} \mathrm{Tb}_{\mathrm{x}} \mathrm{Mn}_{1 / 2} \mathrm{Sc}_{1 / 2} \mathrm{O}_{3}$ vs. temperature under an applied field of 100 Oe. Lines are fits to the Curie-Weiss law.

Figure 6. The zero-field cooled $-\mathrm{ZFC}$, open symbols — and field cooled - FC, black symbols - molar susceptibility $(\mathrm{M} / \mathrm{H})$ of $\mathrm{La}_{1-\mathrm{x}} \mathrm{Tb}_{\mathrm{x}} \mathrm{Mn}_{1 / 2} \mathrm{Sc}_{1 / 2} \mathrm{O}_{3}(\mathrm{x} \leq 0.4)$ under 100 Oe magnetic field. Inset: ZFC and FC curves for $\mathrm{x} \geq 0.5$ compounds.

Figure 7. The zero-field cooled - ZFC, open symbols - and field cooled - FC, black symbols - molar susceptibility $(\mathrm{M} / \mathrm{H})$ of $\mathrm{La}_{0.6} \mathrm{~Tb}_{0.4} \mathrm{Mn}_{1 / 2} \mathrm{Sc}_{1 / 2} \mathrm{O}_{3}$ and $\mathrm{La}_{0.4} \mathrm{~Tb}_{0.6} \mathrm{Mn}_{1 / 2} \mathrm{Sc}_{1 / 2} \mathrm{O}_{3}$ under 100 and $2500 \mathrm{Oe}$ magnetic field.

Figure 8. Isothermal magnetization at $5 \mathrm{~K}$ for $\mathrm{La}_{1-\mathrm{x}} \mathrm{Tb}_{\mathrm{x}} \mathrm{Mn}_{1 / 2} \mathrm{Sc}_{1 / 2} \mathrm{O}_{3}$.

Figure 9. In phase ( $\left.\chi^{\prime}\right)$ and out-of-phase ( $\chi$ ”) initial $\mathrm{AC}$ magnetic susceptibility for (a) $\mathrm{LaMn}_{1 / 2} \mathrm{Sc}_{1 / 2} \mathrm{O}_{3}$, (b) $\mathrm{La}_{0.8} \mathrm{~Tb}_{0.2} \mathrm{Mn}_{1 / 2} \mathrm{Sc}_{1 / 2} \mathrm{O}_{3}$, (c) $\mathrm{La}_{0.5} \mathrm{~Tb}_{0.5} \mathrm{Mn}_{1 / 2} \mathrm{Sc}_{1 / 2} \mathrm{O}_{3}$ and (d) $\mathrm{TbMn}_{1 / 2} \mathrm{Sc}_{1 / 2} \mathrm{O}_{3}$. We have used a fixed $\mathrm{AC}$ field of $4 \mathrm{Oe}$. The arrows indicate the frequency increase direction and the square in (b) marks the crossover region (see text).

Figure 10. Fits for the frequency dependence of $T_{p}$ using the (a) Vogel-Fulcher and (b) power laws. 
Figure 1.

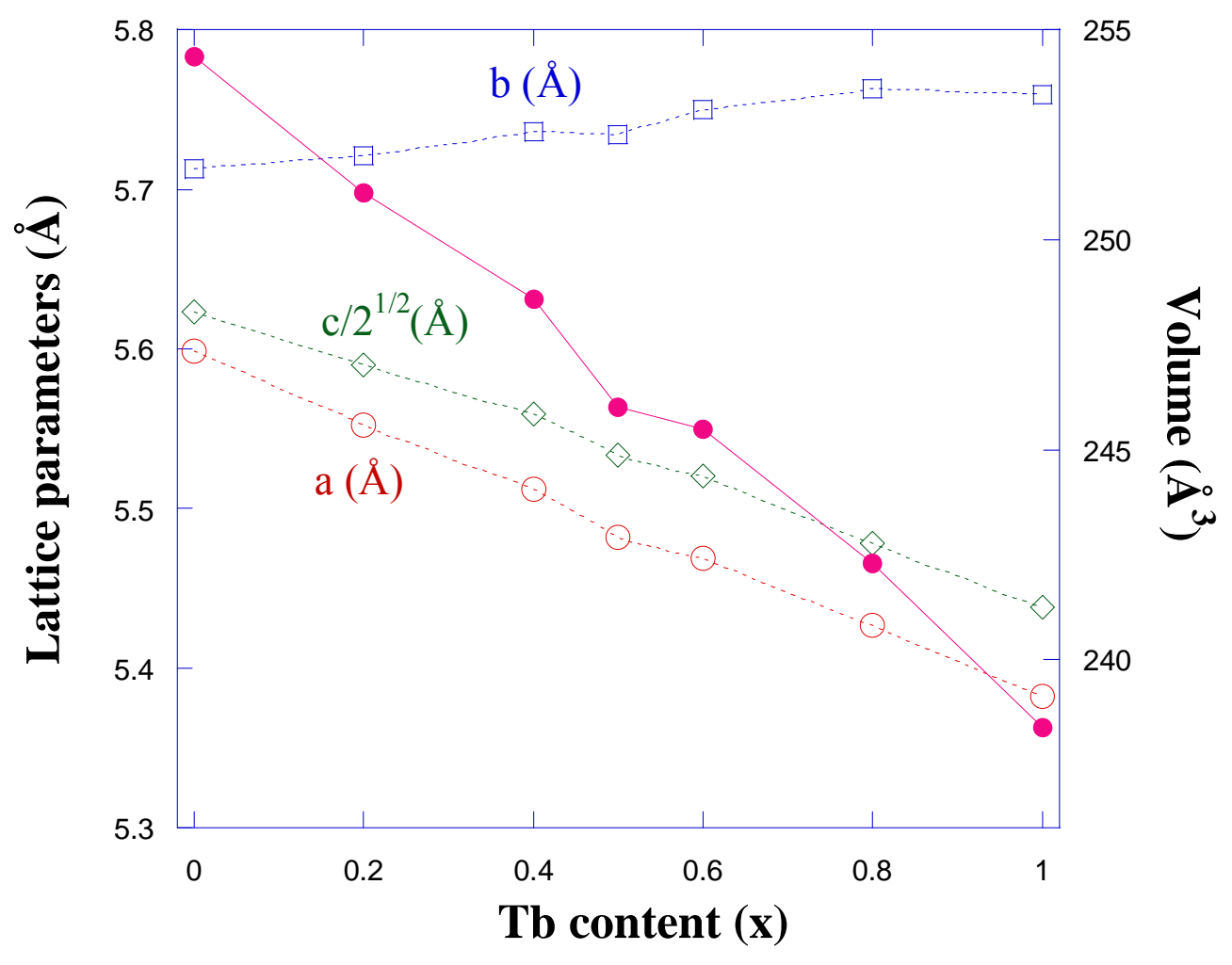


Figure 2.
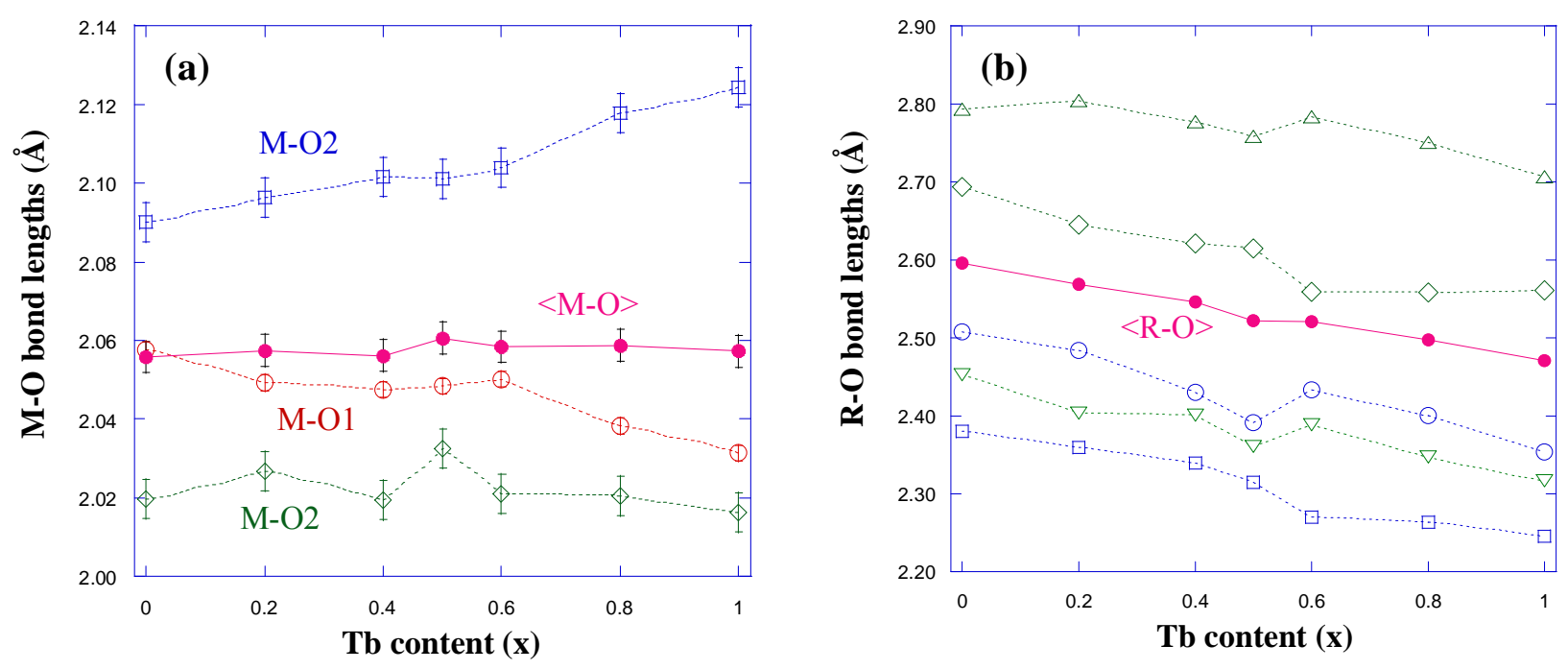

Figure 3.

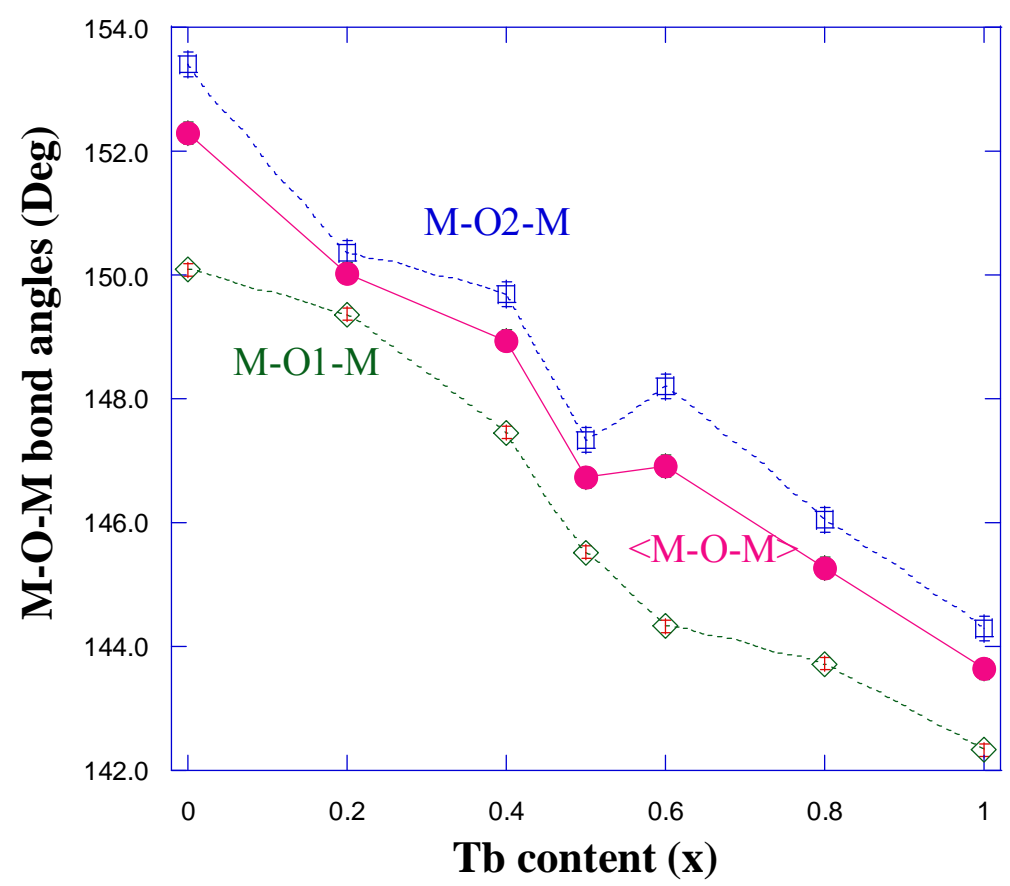


Figure 5.

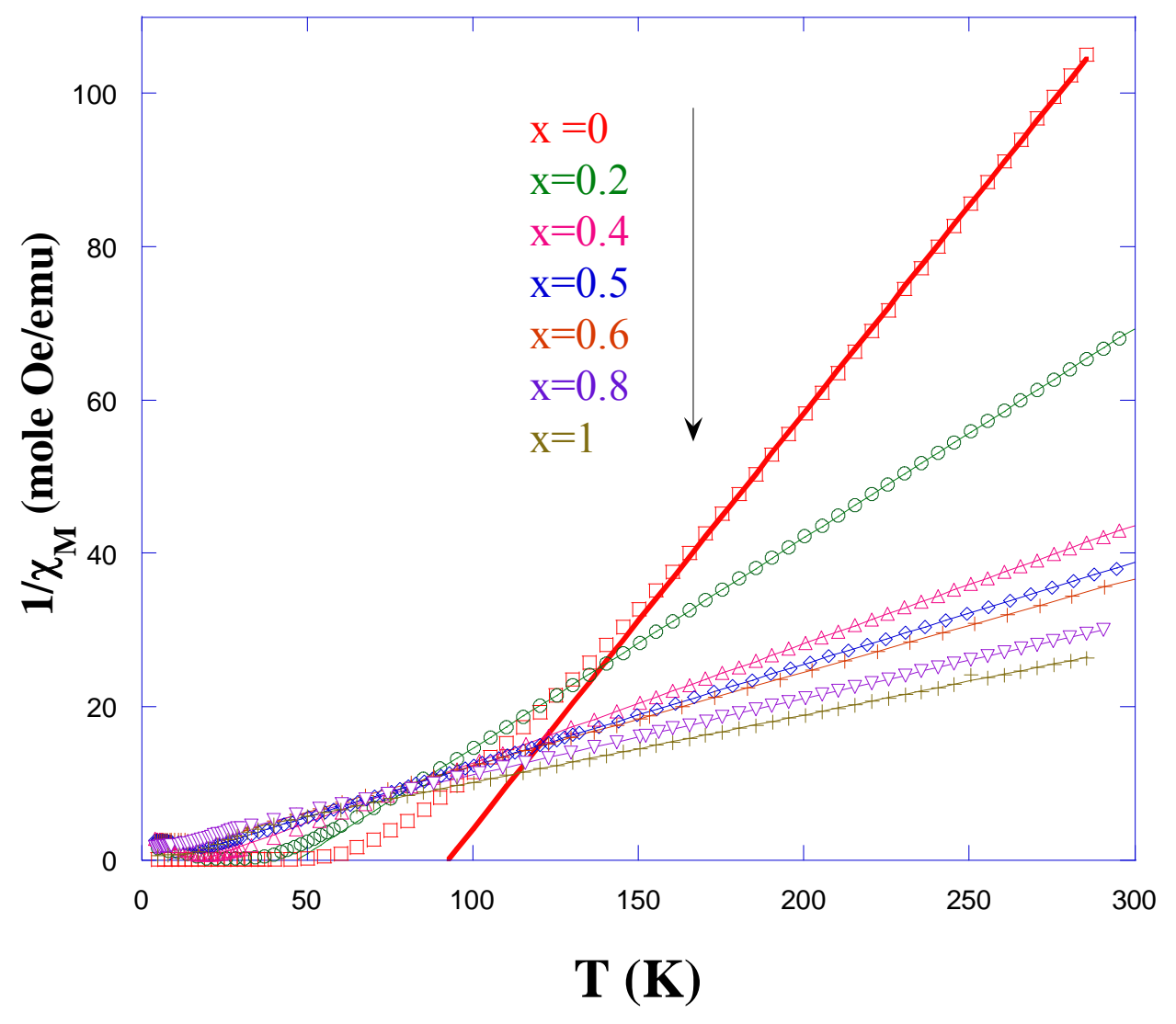


Figure 6.

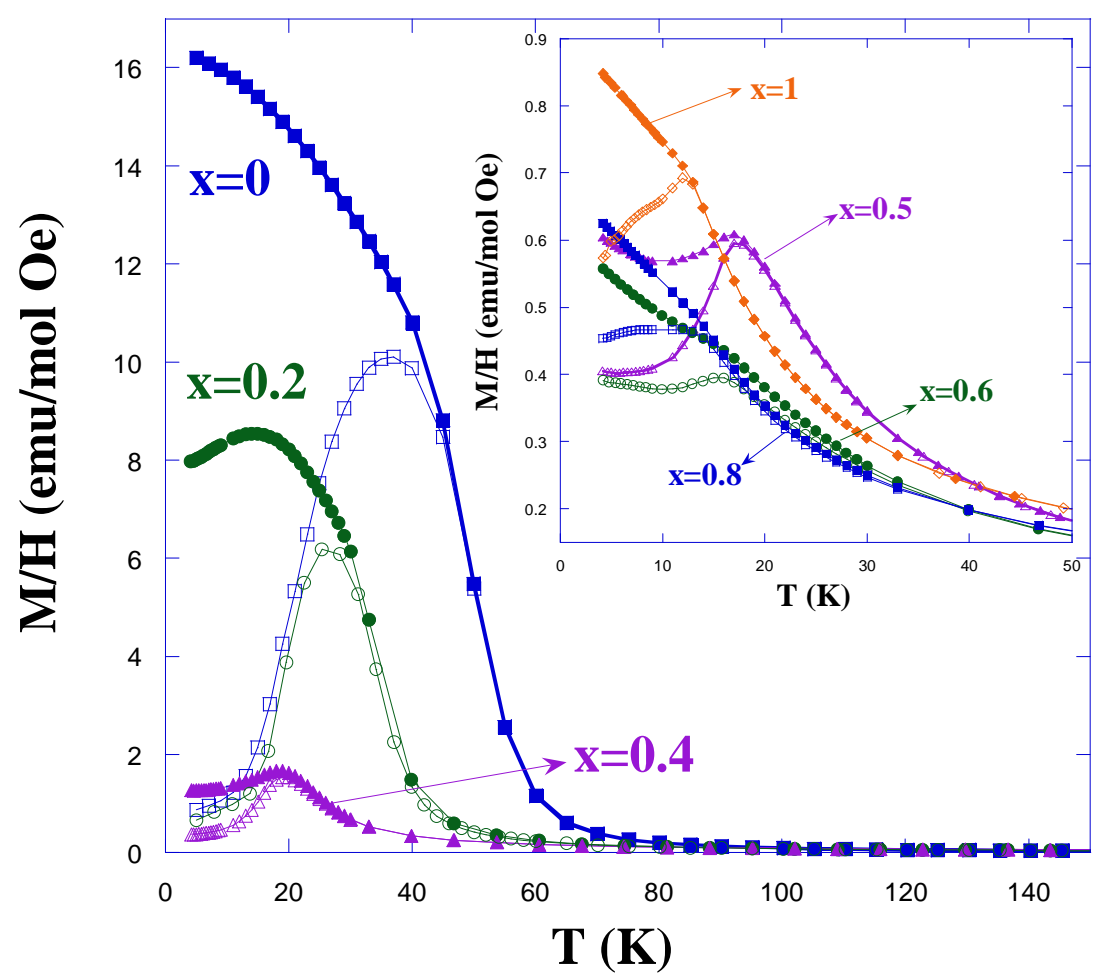

Figure 7.

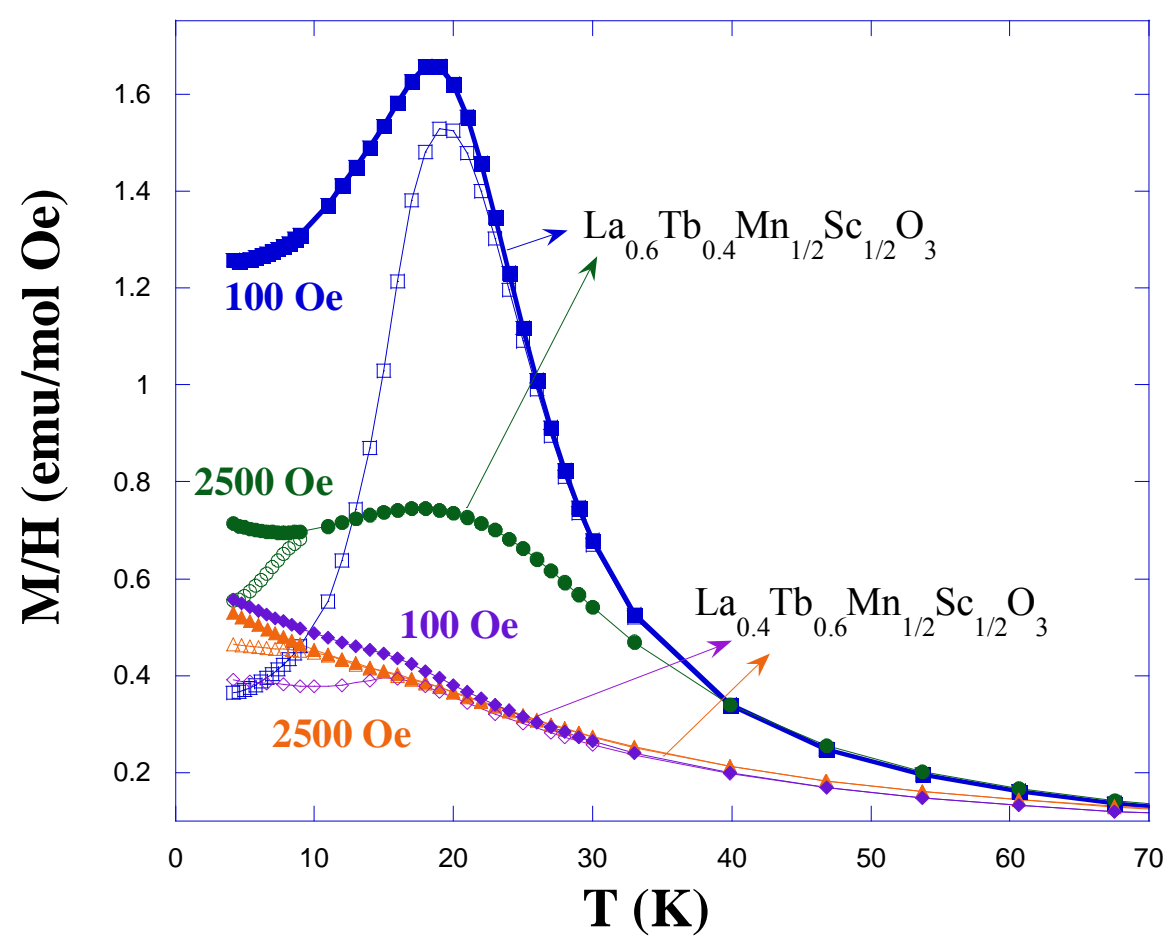


Figure 8.

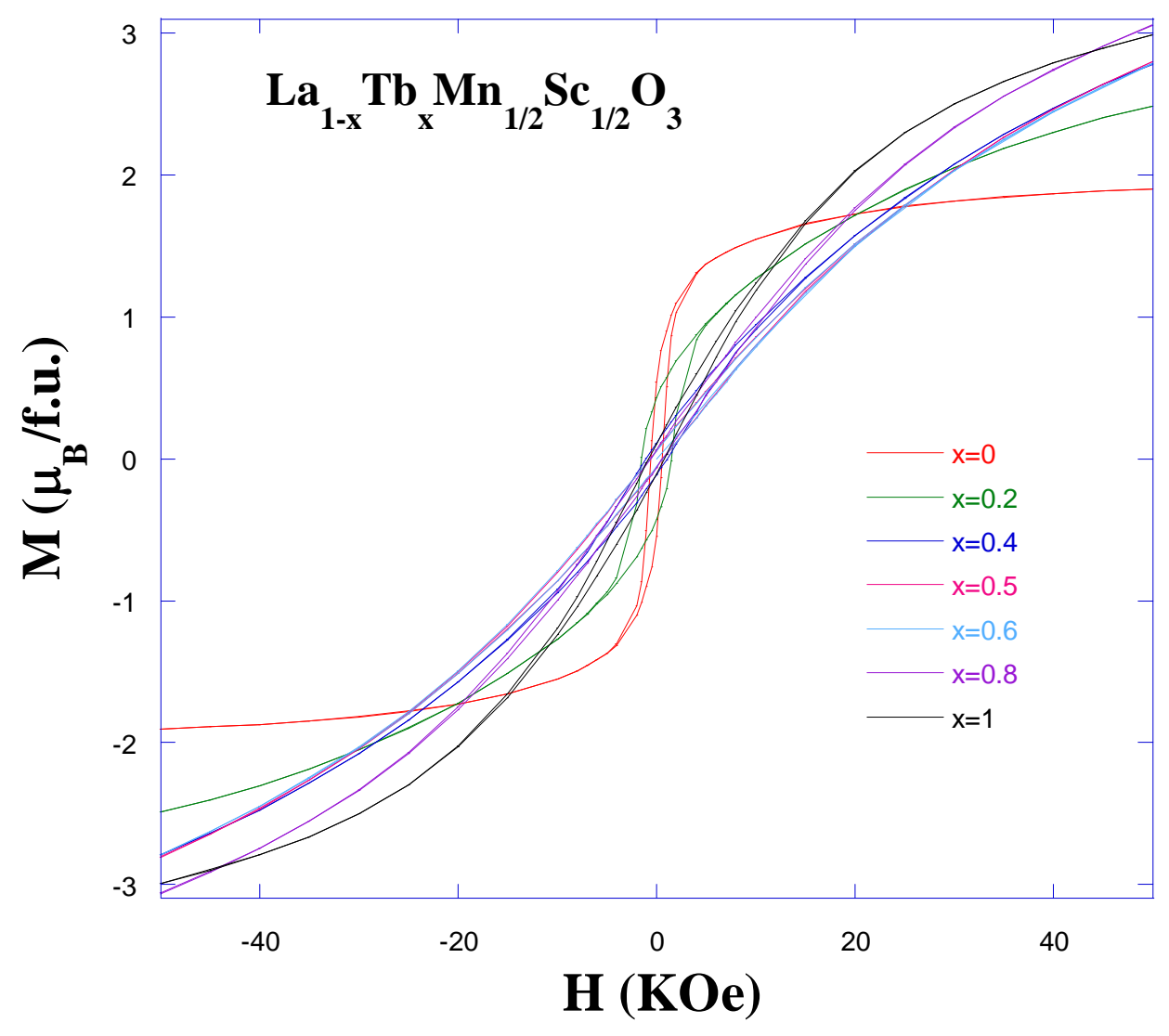


Figure 9.
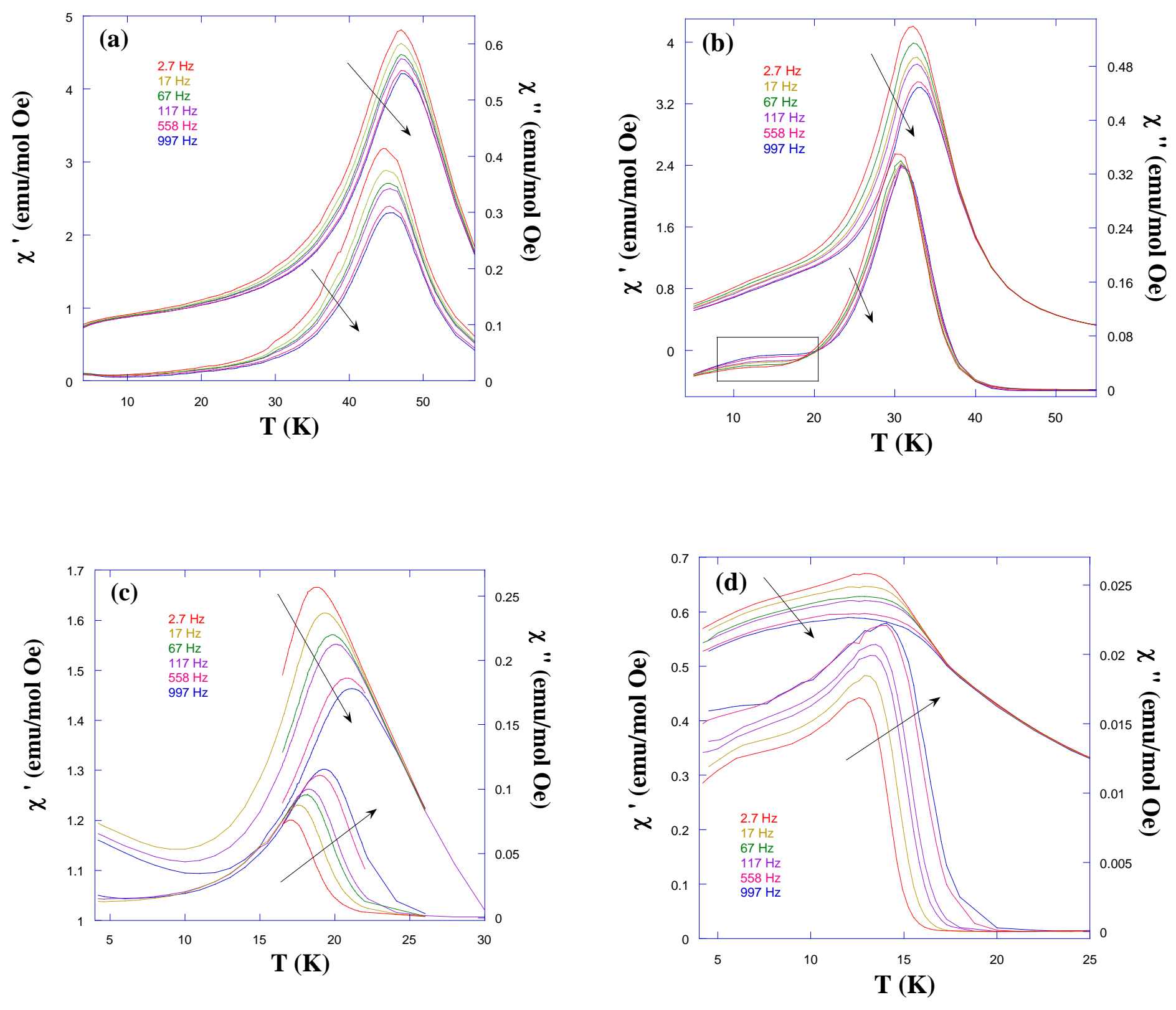
Figure 10.
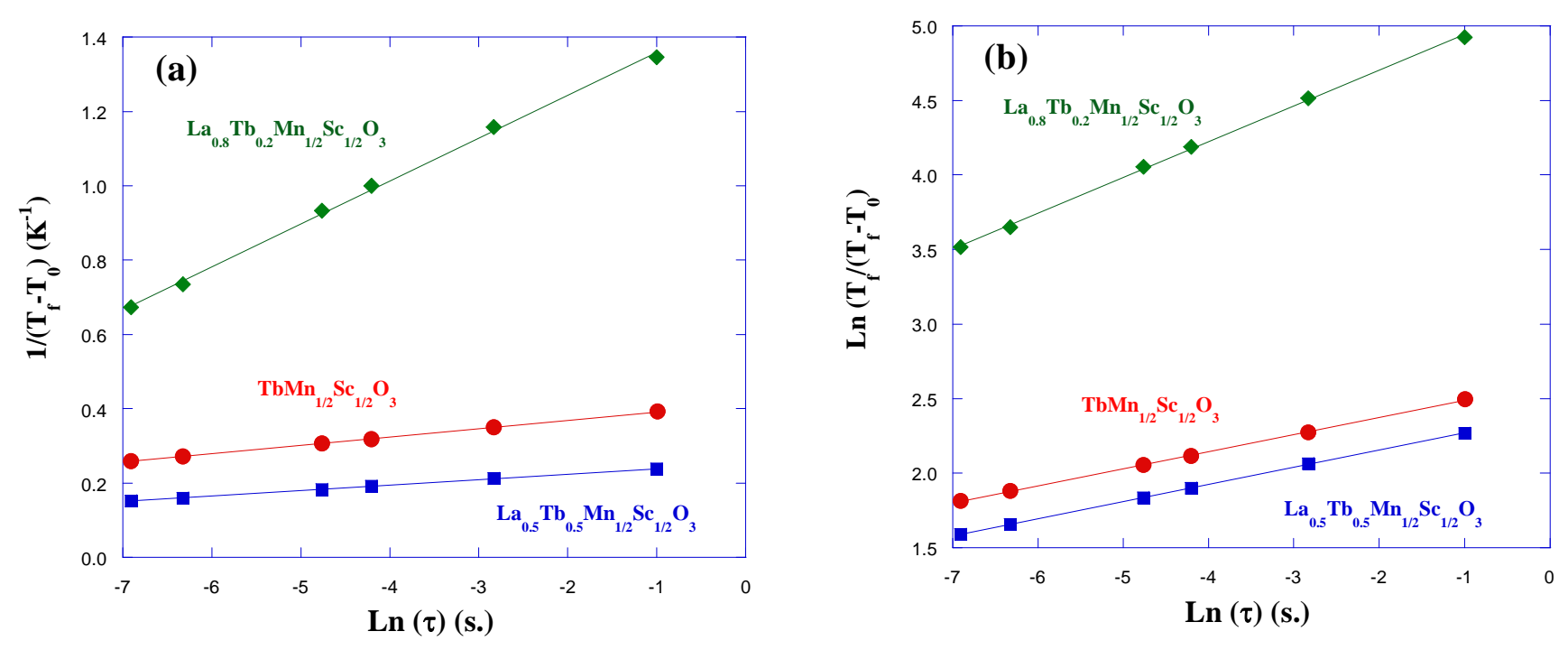